\title{
Leptine and its Role in the Regulation of Appetite and the Development of Obesity
}

Fanny Johanna Villabona Leal ${ }^{1 *}$, Carlos Andrés Guerrero Mejía ${ }^{2}$, Claudia Marcela Berrio Vargas ${ }^{3}$, Juan Camilo Negrete Pico $^{3}$, Tatiana María Berrocal Hoyos ${ }^{4}$, Natalia Aparicio Ríos ${ }^{5}$

${ }^{\mathrm{T}}$ Family Physician, Universidad El Bosque, Colombia

${ }^{2}$ General Physician, Fundación Universitaria San Martin, Colombia

${ }^{3}$ General Physician, Universidad del Sinú, Montería

${ }^{4}$ General Physician, Universidad Libre, Barranquilla

${ }^{5}$ General Physician, Fundación Universitaria Autónoma de las Américas, Colombia

DOI: $10.36347 /$ sjams.2022.v10i01.016

| Received: 01.11.2021 | Accepted: 04.12.2021 | Published: 20.01.2022

*Corresponding author: Fanny Johanna Villabona Leal

Abstract

Original Research Article

Background: Leptin, a $160 \mathrm{kDa}$ hormone produced and secreted by adipose tissue in direct relation to the amount of body fat. 1.9 billion adults have been identified as overweight and more than 650 million overweight adults are obese. Hyperleptinemia and resistance to reduction in body mass are two common characteristics of obesity. Methodology: A narrative review was carried out through various databases from January 2009 to November 2021; the search and selection of articles was carried out in journals indexed in English. Keywords were used: Leptin, obesity, appetite, anorexia. Results: Leptin has its main site of action in the brain, at the level of the brain stem and the hypothalamus. In order to modulate satiety and control of reward and aversion. As the amount of adipose tissue decreases, the amount of leptin produced that crosses the blood-brain barrier decreases. Conclusions: This review offers updated information on the association between Leptin and its role in the regulation of appetite and the development of obesity.

Keywords: Leptin, Obesity, Appetite, anorexia.

Copyright $\odot 2022$ The Author(s): This is an open-access article distributed under the terms of the Creative Commons Attribution 4.0 International License (CC BY-NC 4.0) which permits unrestricted use, distribution, and reproduction in any medium for non-commercial use provided the original author and source are credited.

\section{INTRODUCTION}

Leptin, a $160 \mathrm{kDa}$ hormone produced and secreted by adipose tissue in direct relation to the amount of body fat. A small increase in leptin concentration reduces appetite and leads to a decrease in body weight. (1) Comorbidities associated with obesity, such as hypertension, dyslipidemia, type 2 diabetes mellitus, fatty liver disease, heart disease, and some types of cancer, caused approximately 3.4 million deaths in adults older than 18 years $[1,2]$.

1.9 billion adults have been identified as overweight and more than 650 million overweight adults are obese. Hyperleptinemia and resistance to reduction in body mass are two common characteristics of obesity. Since a strong association between leptin and obesity has been shown, pharmaceutical companies pursue the idea of using leptin-based drugs as a therapeutic strategy for weight loss [3].

Leptin regulates food intake, body mass, reproductive functioning, and plays a vital role in fetal growth, pro-inflammatory immune responses, angiogenesis, and lipolysis. Studies showed that the circulating leptin concentration decreases during fasting or energy restriction, but increases during refeeding, overfeeding, as well as during surgical stress [4].

When fat cells increase, leptin levels increase proportionally and then bind to leptin receptors (LEP$\mathrm{R}$ ) in the brain that send signals to inhibit food intake and increase energy expenditure [4]. Given the high rates of obesity, this study should be carried out to provide updated information on the association with leptin and its role in the regulation of appetite and the development of obesity.

\section{Materials And Methods}

A narrative review was carried out, in which the PubMed, Scielo and ScienceDirect databases, among others, were searched. The collection and selection of articles was carried out in journals indexed in English from 2009 to 2021. As keywords, the following terms were used in the databases according to 
the DeCS and MeSH methodology: Leptin; obesity; Appetite; Anorexy. In this review, 74 original and review publications related to the subject studied were identified, of which 20 articles met the specified inclusion requirements, such as articles that were in a range not less than the year 2009, which were articles of full text and to report on Leptin and its role in the regulation and development of obesity. As exclusion criteria, it was taken into account that the articles did not have enough information and that they did not present the full text at the time of their review.

\section{ReSUlTS APPETITE REGULATORY MECHANISM}

Leptin's main site of action is the brain, specifically the brain stem and hypothalamus. The main sites of action in the brainstem are the solitary tract and the ventral tegmental area. Leptin acts here to modulate satiety and the control of reward and aversion (Figure 1). In the hypothalamus, the lateral hypothalamic area and the ventromedial, dorsomedial, ventral premamillary, and arcuate nuclei (ARC) are the main sites of action of leptin [5].

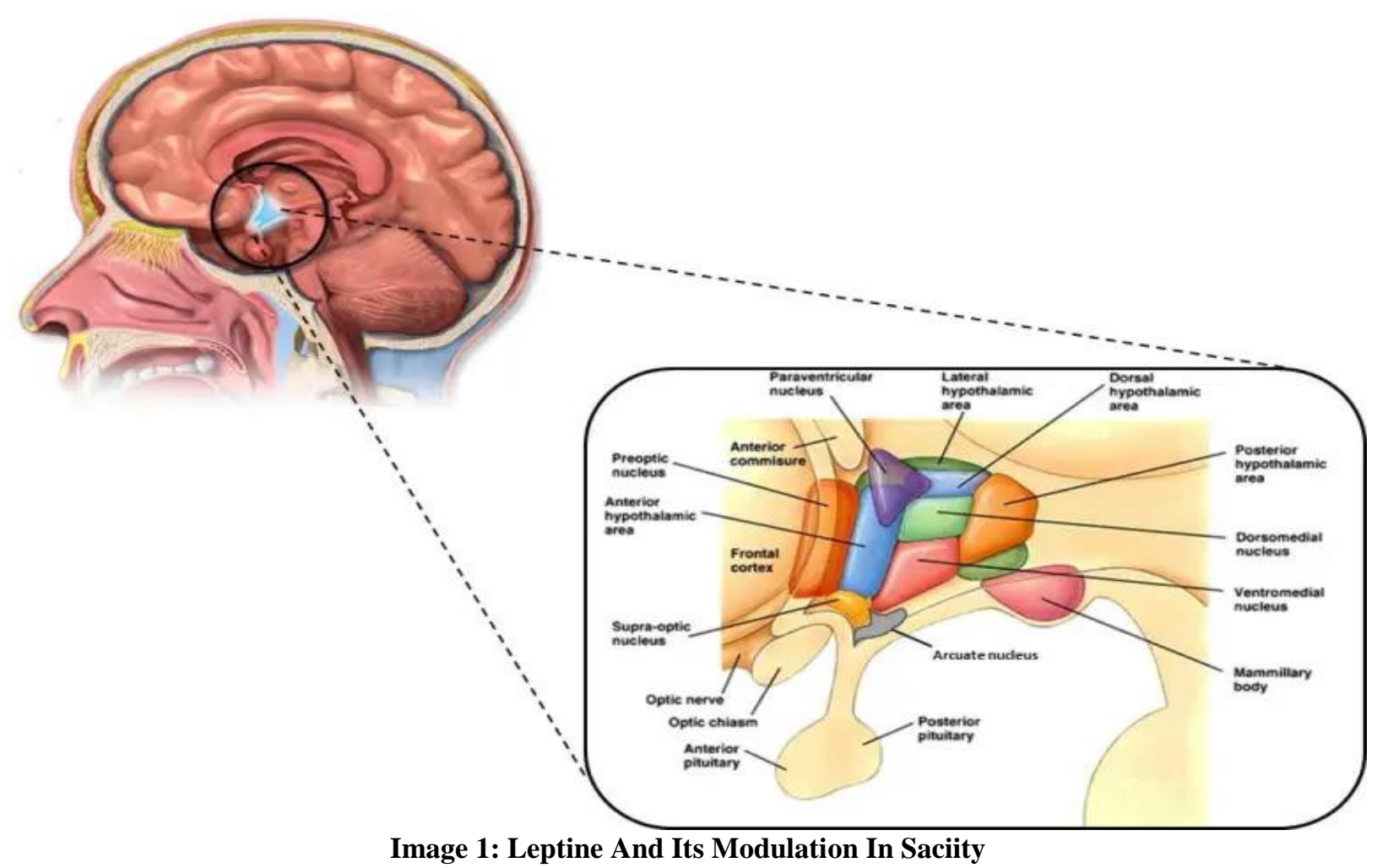

Leptin interacts with a complex neuronal circuit to control intake through two main mechanisms: a. The stimulation of neurons that synthesize two proteins with anorectic properties (which reduce hunger): proopiomelanocortin (POMC) and transcription regulated by cocaine and amphetamine. $b$. Inhibition of neurons that synthesize two orexigenic proteins (which stimulate hunger): neuropeptide $\mathrm{Y}$ (NPY) and r-agouti protein (AgRP).

These hypothalamic areas lead to several changes, including the thyroid, gonadal, adrenocorticotropic hormone-growth hormone cortisol axes, and changes in cognition, emotions, memory, and the structure of the entire brain [6].

Leptin acts on the ARC Nucleus. The ARC nucleus is an important actor in appetite regulation and energy homeostasis. It contains orexigenic neurons that contain protein and neuropeptide, related to agouti and anorectic neurons that contain proopiomelanocortin (POMC) [7].

Leptin acts on the ARC nucleus by stimulating POMC-containing neurons and inhibiting AgRP / NPYcontaining neurons, which has the overall effect of appetite reduction [8].

The role of leptin in the body refers to regulating the balance between food intake and energy expenditure. The classic primary physiological function of leptin is to serve as a marker of long-term energy reserves for the central nervous system (CNS) $[8,9]$.

As the amount of adipose tissue decreases, the amount of leptin produced that crosses the blood-brain barrier decreases. The CNS interrupts the decline in leptin as an energy deficit signal, triggering a cascade of responses to help the body cope with the stress of starvation $[9,7]$. 
To counteract the energy deficit, the CNS increases hunger while promoting energy-saving neuroendocrine and autonomic mechanisms, including lowering the tone of the sympathetic nervous system, levels of thyroid and reproductive hormones, energy expenditure and increase $[10,6]$.

As a signal, leptin is the catalyst for the body's transition to starvation mode, a global adaptation aimed at increasing food intake and decreasing energy expenditure [11].

It has been shown that the decrease in serum leptin is the starvation signal for the CNS. As food intake increases and the level of adipose tissue becomes excessive, there is a simultaneous increase in the production and secretion of leptin in the bloodstream $[12,7]$. With the increase in leptin there is an inhibition of the body's starvation mode, which promotes a reduced food intake and a higher energy expenditure to counteract the current energy surplus.

\section{LEPTIN DISORDERS ASSOCIATED WITH OBESITY}

Among the main leptin alterations associated with obesity, we find hypoleptinemia and hyperleptinemia. These alterations have different pathophysiological mechanisms, but both have been associated with obesity, in Table 1, we can see the mechanisms that compose it $[11,12]$.

Table 1: Leptin and obesity

\begin{tabular}{|l|l|}
\hline $\begin{array}{l}\text { LEPTINE } \\
\text { ALTERATIONS }\end{array}$ & PROPOSED MECHANISMS \\
\hline Hypoleptinemia & $\begin{array}{l}\text { Complete leptin deficiency results in the clinical phenotypes of severe obesity, impaired satiety, severe } \\
\text { hyperphagia, constant food-seeking behavior. } \\
\text { 1. Congenital forms. They are the result of mutations in the LEP or LR gene and are known as congenital } \\
\text { leptin deficiencies (CLD). } \\
\text { 2. Acquired forms. They share some of these same phenotypes and are generally due to conditions that } \\
\text { cause low body weight. Example: Syndromes of lipodystrophy and hypothalamic amenorrea [13]. }\end{array}$ \\
\hline Hyperleptinemia & $\begin{array}{l}\text { Hyperleptinemia is associated with leptin resistance, specifically resistance to the anorexic and body } \\
\text { weight-lowering effects of leptin. Hyperleptinemia and leptin resistance are components of common obesity } \\
\text { [10,8]. } \\
\text { Evidence for this association is a direct correlation between serum leptin concentrations and body fat } \\
\text { percentage where obese individuals had higher serum leptin levels and adipocyte LEP mRNA content } \\
\text { compared to normal weight individuals. In addition, the serum leptin levels and the LEP of adipocytes, the } \\
\text { content of mRNA decreases with the reduction of weight. The resistance mechanism appears to be related } \\
\text { to defects in leptin transport across the blood-brain barrier or intracellular signaling mechanisms [10, 4]. }\end{array}$ \\
\hline
\end{tabular}

\section{IS THE HEMATENEPHALIC BARRIER ASSOCIATED WITH OBESITY?}

Given that Leptin crosses the blood-brain barrier to exert its function in the regulation of appetite, it could at the same time be associated as a pathophysiological mechanism resulting in obesity [13].

The blood-brain barrier is made up of several highly specialized cell types that protect the brain from toxic substances and regulate the passage of macromolecules, as well as the bidirectional transport of nutrients and hormones between the blood and the brain [14].

Food intake and metabolism are regulated by different hormones, such as leptin, the circulating levels of which must be regulated very precisely and are often altered in obesity [15]. These hormones must reach the brain by crossing the blood-brain barrier via a specific transporter.

It has been shown that obesity can generate pathological changes in the cellular integrity of the blood-brain barrier, independently of the transporters, which can aggravate the pathological situation at the level of the central nervous system [16].
Leptin is transported across the blood-brain barrier by the leptin receptor, which is, therefore, subject to regulatory mechanisms of membrane receptors, it is expected that high levels of circulating leptin can activate the mechanisms of desensitization and regulation downward, causing the degradation of these receptors [17].

Resistance to leptin at the blood-brain barrier has been attributed to receptor saturation effects exerted by excess leptin or reversible inhibition caused by circulating factors such as triglycerides [18].

New studies have questioned the proclaimed decrease in leptin transport across the blood-brain barrier in obese individuals, thus opening up the idea of leptin resistance unrelated to transport across the bloodbrain barrier. Of which these mechanisms are still not entirely clear $[19,20]$.

\section{Discussion AND CONCLUTION}

Leptin has its main site of action in the brain, at the level of the brain stem and the hypothalamus. In order to modulate satiety and the control of reward and aversion. As the amount of adipose tissue decreases, the amount of leptin produced that crosses the blood-brain barrier decreases. 
Fanny Johanna Villabona Leal et al; Sch J App Med Sci, Jan, 2022; 10(1): 97-100

The CNS interrupts the decline in leptin as an energy deficit signal, triggering a cascade of responses to help the body cope with the stress of starvation [4, 13]. Among the main alterations of leptin we can find the clinical phenotypes of severe obesity, alteration of satiety, hyperphagia, as well as anorexic and body weight-reducing effects of leptin [7].

A strength of the current study is the methodology implemented, with respect to the literature search, and steps in the selection of relevant articles, quality assessment and data extraction. However, this study has several limitations, which should be taken into account before reaching a conclusion, within these are the little evidence from analysis of clinical trials to determine the therapeutic or pharmacological approach that can be established between leptin and development obesity.

\section{REFERENCES}

1. Izquierdo, A. G., Crujeiras, A. B., Casanueva, F. F., \& Carreira, M. C. (2019). Leptin, obesity, and leptin resistance: where are we 25 years later?. Nutrients, 11(11), 2704.

2. Gruzdeva, O., Borodkina, D., Uchasova, E., Dyleva, Y., \& Barbarash, O. (2019). Leptin resistance: underlying mechanisms and diagnosis. Diabetes, metabolic syndrome and obesity: targets and therapy, 12, 191-198.

3. Obradovic, M., Sudar-Milovanovic, E., Soskic, S., Essack, M., Arya, S., Stewart, A. J., ... \& Isenovic, E. R. (2021). Leptin and Obesity: Role and Clinical Implication. Frontiers in Endocrinology, 12, 585887.

4. Myers Jr, M. G., Leibel, R. L., Seeley, R. J., \& Schwartz, M. W. (2010). Obesity and leptin resistance: distinguishing cause from effect. Trends in Endocrinology \& Metabolism, 21(11), 643-651.

5. Kumar, R., Mal, K., Razaq, M. K., Magsi, M., Memon, M. K., Memon, S., ... \& Rizwan, A. (2020). Association of Leptin With Obesity and Insulin Resistance. Cureus, 12(12), e12178.

6. Francisco, V., Pino, J., Campos-Cabaleiro, V., Ruiz-Fernández, C., Mera, A., Gonzalez-Gay, M. A., ... \& Gualillo, O. (2018). Obesity, fat mass and immune system: role for leptin. Frontiers in physiology, 9, 640.

7. Zhou, Y., \& Rui, L. (2013). Leptin signaling and leptin resistance. Frontiers of medicine, 7(2), 207222.

8. Landecho, M. F., Tuero, C., Valentí, V., Bilbao, I., de la Higuera, M., \& Frühbeck, G. (2019). Relevance of leptin and other adipokines in obesity-associated cardiovascular risk. Nutrients, 11(11), 2664.
9. Friedman, J. M. (2011). Leptin and the regulation of body weigh. The Keio journal of medicine, 60(1), 1-9.

10. Ekmen, N., Helvaci, A., Gunaldi, M., Sasani, H., \& Yildirmak, S. T. (2016). Leptin as an important link between obesity and cardiovascular risk factors in men with acute myocardial infarction. Indian Heart Journal, 68(2), 132-137.

11. Kelesidis, T., Kelesidis, I., Chou, S., \& Mantzoros, C. S. (2010). Narrative review: the role of leptin in human physiology: emerging clinical applications. Annals of internal medicine, 152(2), 93-100.

12. Genchi, V. A., D’Oria, R., Palma, G., Caccioppoli, C., Cignarelli, A., Natalicchio, A., ... \& Perrini, S. (2021). Impaired Leptin Signalling in Obesity: Is Leptin a New Thermolipokine?. International Journal of Molecular Sciences, 22(12), 6445.

13. Marrodan, M., Farez, M. F., Balbuena Aguirre, M. E., \& Correale, J. (2021). Obesity and the risk of Multiple Sclerosis. The role of Leptin. Annals of Clinical and Translational Neurology, 8(2), 406424.

14. Simonds, S. E., Pryor, J. T., Ravussin, E., Greenway, F. L., Dileone, R., Allen, A. M., ... \& Cowley, M. A. (2014). Leptin mediates the increase in blood pressure associated with obesity. Cell, 159(6), 1404-1416.

15. Chrysafi, P., Perakakis, N., Farr, O. M., Stefanakis, K., Peradze, N., Sala-Vila, A., \& Mantzoros, C. S. (2020). Leptin alters energy intake and fat mass but not energy expenditure in lean subjects. Nature communications, 11(1), 1-15.

16. Dopytalska, K., Baranowska-Bik, A., Roszkiewicz, M., Bik, W., \& Walecka, I. (2020). The role of leptin in selected skin diseases. Lipids in Health and Disease, 19(1), 1-10.

17. Wasim, M., Awan, F. R., Najam, S. S., Khan, A. R., \& Khan, H. N. (2016). Role of leptin deficiency, inefficiency, and leptin receptors in obesity. Biochemical Genetics, 54(5), 565-572.

18. Peelman, F., Zabeau, L., Moharana, K., Savvides, S. N., \& Tavernier, J. (2014). 20 years of leptin: insights into signaling assemblies of the leptin receptor. Journal of Endocrinology,223(1), T9T23.

19. Allison, M. B., \& Myers Jr, M. G. (2014). Connecting leptin signaling to biological function. The Journal of endocrinology, 223(1), T25-35

20. Amjad, S., Baig, M., Zahid, N., Tariq, S., \& Rehman, R. (2019). Association between leptin, obesity, hormonal interplay and male infertility. Andrologia, 51(1), e13147. 